\title{
PERCEPTION OF DAIRY FARMERS REGARDING EFFECTIVENESS OF ARTIFICIAL INSEMINATION SERVICES OF DIFFERENT DAIRY SERVICE DELIVERY SYSTEMS
}

\author{
S. KARTHIKEYAN*, M. C. ARUNMOZHI DEVI ${ }^{1}$ \\ N. NARMATHA AND V. UMA \\ Department of Veterinary and Animal Husbandry Extension Education \\ Veterinary College and Research Institute \\ TANUVAS, Namakkal-637 002, India
}

\begin{abstract}
The perceived effectiveness of artificial insemination (AI) services offered by different dairy service delivery systems was studied in Namakkal district of Tamilnadu. A total of 120 respondents availing AI services from different dairy service delivery systems were selected using proportionate random sampling and data were collected and analyzed. Dairy co-operatives, private integrators, public departments, private veterinarians and para-veterinarians were the major AI service providers to the dairy farmers in the study area with nearly three-fourth of them have availed the service from the para-veterinarians $\mathbf{7 5 . 8 3 \%}$ ) followed by private veterinarians $(\mathbf{5 7 . 5 0} \%)$. The services of dairy co-operatives and private integrators were perceived to be cost effective with good conception rate but poor in quality and timeliness. The AI service of private veterinarians was perceived to be good in quality and timeliness with better conception rate, but costly. Overall it was perceived that artificial insemination service offered by public departments through veterinary dispensary and sub-centre were the best among other service providers because of their cheap, quality and timely delivery of service coupled with better conception rate.
\end{abstract}

Key words: Artificial insemination, Conception, Effectiveness, Timeliness, Quality

Among various dairy innovations in India, artificial insemination (AI) has been considered as an important dairy innovation of socio-economic importance in Indian dairy industry (Rathod and Chander, 2014). $\mathrm{AI}$ is one of the most efficient techniques available to dairy farmers to improve productivity and profitability of their enterprise. In artificial insemination, the fewer bulls of superior quality can be efficiently used to expand the breeding coverage for large number of dairy cows regardless of their distant location.

The efficient delivery of artificial insemination has become a subject of rising concern to many national and international organisations such as FAO, World Bank and

*Corresponding Author

${ }^{1}$ Dairy Extension Division, National Dairy Research Institute, Southern Regional Station, Bangalore 
ILRI in India. Recognising the importance of livestock for the rural poor and their limited financial access to these livestock support, the central and state governments have been extending these services at a huge subsidy (Pushpa and Chandel, 2014).

A vast network of veterinary institutions offers breeding services to the farmers at very low prices. In a pluralistic environment with different dairy service providers, it is important to assess their effectiveness on various criteria in order to identify the best system in terms of their service delivery. On this background, the present study was undertaken to analyze the effectiveness of artificial insemination service offered by the different dairy service delivery systems as perceived by the dairy farmers.

\section{MATERIALS AND METHODS}

The study was conducted in Namakkal district of Tamil Nadu state. All the four taluks of Namakkal district were purposively included for the study. From each taluk, one village having highest bovine population was selected for the research study. Respondents were selected based on the criteria that the selected individual should be rearing milch animal either a cow or a buffalo in milking condition and should be availing services from different dairy service delivery systems aforementioned. The different milk procurement channels available in the selected villages were considered as strata and a total sample of 30 respondents from each village was selected proportionately from each stratum by proportionate random sampling method. Thus, a total of 120 respondents were selected for the study and the data were collected by personal interview method using pre-tested interview schedule. The perceived effectiveness of different dairy service delivery systems for artificial insemination services was ascertained in terms of timeliness, supply of semen of varied breeds, quality, conception and cost effectiveness. The scores were assigned on a three - point continuum for the indicators in order to analyze their perceived effectiveness. Weighted score for each dairy service delivery system was calculated by assigning 3 for 'good', 2 for 'average' and 1 for 'poor' then multiply the per cent of observation by the respective score and finally adding the total observation.

\section{RESULTS}

AI service availed from different dairy service delivery systems: It could be concluded from Table 1 that there were five major service providers who were providing artificial insemination service to the dairy farmers in the study area. Nearly three-fourth of the respondents $(75.83 \%)$ had availed the service from the para-veterinarians predominantly followed by the services of the private veterinarians $(57.50 \%)$. About one-third $(34.17 \%)$ of the respondents had availed the insemination service from the public departments. However, the insemination services of dairy co-operatives and private integrators were availed by the $21.67 \%$ and $12.50 \%$ of the dairy farmers which were being delivered in the cooperative society as well as in their door step by veterinarians and inseminators trained by the co-operatives and integrators. 
Table 1. Artificial Insemination service availed from different dairy service delivery systems

\begin{tabular}{llcr}
\hline $\begin{array}{c}\text { Sl. } \\
\text { No }\end{array}$ & $\begin{array}{c}\text { Dairy service delivery systems } \\
(\mathbf{n = 1 2 0})\end{array}$ & \multicolumn{2}{c}{ Artificial Insemination Service } \\
\cline { 3 - 4 } & & Frequency* & Per cent \\
\hline 1 & Dairy co-operatives & 26 & 21.67 \\
2 & Private integrators & 15 & 12.50 \\
3 & Public departments & 41 & 34.17 \\
4 & Private veterinarians & 69 & 57.50 \\
5 & Para-veterinarians & 91 & 75.83 \\
\hline
\end{tabular}

Perceived effectiveness of AI service of different dairy service delivery systems: Table 2 shows the perceived effectiveness of artificial insemination service offered by different dairy service delivery systems.

Timeliness: With a weighted score of 297.56, the insemination service of public departments was perceived to be the best among the different service providers in their timeliness. It was perceived that the services of private veterinarians and paraveterinarians were also available to the dairy farmers at appropriate time with weighted scores of 284.06 and 282.42 respectively. However, the dairy cooperatives (253.85) and private integrators (246.67) were perceived as not so effective in timely delivery of insemination services to the dairy farmers.

Semen of varied breeds: Public department was perceived to be highly effective than other service providers in providing insemination service using the semen from various improved breeds with a weighted score of 282.93. But the other insemination service providers viz., dairy co-operatives
(250.00), private integrators (260.00), private veterinarians $(257.97)$ and paraveterinarians (257.14) were perceived to be moderately effective in supplying the semen of various indigenous and exotic breeds.

Quality: The quality of the insemination service offered by public departments (300.00) was perceived to be best followed by the services of private veterinarians (297.10) and private integrators (293.33). The quality of insemination service offered by the dairy co-operatives (273.08) and para-veterinarians (275.82) were perceived to be not so effective as that of others.

Conception: The dairy farmers perceived that best conception rate was noticed in insemination service of the public departments with a weighted score of 292.68. Similarly, the insemination services of private veterinarians, dairy co-operatives and private integrators also perceived to have better conception as that of public departments with weighted scores of $286.96,284.62$ and 280.00 respectively. However, the conception with the 
Table 2. Perceived effectiveness of AI service offered by different service providers

\begin{tabular}{|c|c|c|c|c|c|}
\hline Timeliness & $\begin{array}{c}\text { Good } \\
(\%) \\
\end{array}$ & $\begin{array}{c}\text { Average } \\
(\%)\end{array}$ & $\begin{array}{c}\text { Poor } \\
(\%)\end{array}$ & $\begin{array}{c}\text { Weighted } \\
\text { score }\end{array}$ & Rank \\
\hline Dairy co-operatives $(\mathrm{n}=26)$ & 65.38 & 23.08 & 11.54 & 253.85 & IV \\
\hline Private integrators $(n=15)$ & 53.33 & 40.00 & 6.67 & 246.67 & $\mathrm{~V}$ \\
\hline Public departments $(n=41)$ & 97.56 & 2.44 & 0.00 & 297.56 & $\mathrm{I}$ \\
\hline Private veterinarians $(n=69)$ & 85.51 & 13.04 & 1.45 & 284.06 & II \\
\hline Para-veterinarians $(\mathrm{n}=91)$ & 85.71 & 10.99 & 3.30 & 282.42 & III \\
\hline Semen of varied breeds & $\begin{array}{c}\text { Good } \\
(\%)\end{array}$ & $\begin{array}{c}\text { Average } \\
(\%)\end{array}$ & $\begin{array}{c}\text { Poor } \\
(\%)\end{array}$ & $\begin{array}{l}\text { Weighted } \\
\text { score }\end{array}$ & Rank \\
\hline$\overline{\text { Dairy co-operatives }(\mathrm{n}=26)}$ & 57.69 & 34.62 & 7.69 & 250.00 & $\mathrm{~V}$ \\
\hline Private integrators $(\mathrm{n}=15)$ & 60.00 & 40.00 & 0.00 & 260.00 & II \\
\hline Public departments $(n=41)$ & 82.93 & 17.07 & 0.00 & 282.93 & I \\
\hline Private veterinarians $(n=69)$ & 60.87 & 36.23 & 2.90 & 257.97 & III \\
\hline Para-veterinarians $(n=91)$ & 61.54 & 34.07 & 4.40 & 257.14 & IV \\
\hline Quality & $\begin{array}{c}\text { Good } \\
(\%)\end{array}$ & $\begin{array}{c}\text { Average } \\
(\%)\end{array}$ & $\begin{array}{c}\text { Poor } \\
(\%) \\
\end{array}$ & $\begin{array}{c}\text { Weighted } \\
\text { score }\end{array}$ & Rank \\
\hline Dairy co-operatives $(\mathrm{n}=26)$ & 73.08 & 26.92 & 0.00 & 273.08 & $\mathrm{~V}$ \\
\hline Private integrators $(\mathrm{n}=15)$ & 93.33 & 6.67 & 0.00 & 293.33 & III \\
\hline Public departments $(n=41)$ & 100.0 & 0.00 & 0.00 & 300.00 & I \\
\hline Private veterinarians $(n=69)$ & 97.10 & 2.90 & 0.00 & 297.10 & II \\
\hline Para-veterinarians $(\mathrm{n}=91)$ & 78.02 & 19.78 & 2.20 & 275.82 & IV \\
\hline Conception & $\begin{array}{c}\text { Good } \\
(\%)\end{array}$ & $\begin{array}{c}\text { Average } \\
(\%)\end{array}$ & $\begin{array}{l}\text { Poor } \\
(\%)\end{array}$ & $\begin{array}{c}\text { Weighted } \\
\text { score }\end{array}$ & Rank \\
\hline Dairy co-operatives $(n=26)$ & 84.62 & 15.38 & 0.00 & 284.62 & III \\
\hline Private integrators $(n=15)$ & 80.00 & 20.00 & 0.00 & 280.00 & IV \\
\hline Public departments $(n=41)$ & 92.68 & 7.32 & 0.00 & 292.68 & I \\
\hline Private veterinarians $(n=69)$ & 88.41 & 10.14 & 1.45 & 286.96 & II \\
\hline Para-veterinarians $(\mathrm{n}=91)$ & 70.33 & 24.18 & 5.49 & 264.84 & $\mathrm{~V}$ \\
\hline Cost effectiveness & $\begin{array}{c}\text { Good } \\
(\%)\end{array}$ & $\begin{array}{c}\text { Average } \\
(\%)\end{array}$ & $\begin{array}{c}\text { Poor } \\
(\%)\end{array}$ & $\begin{array}{c}\text { Weighted } \\
\text { score }\end{array}$ & Rank \\
\hline Dairy co-operatives $(\mathrm{n}=26)$ & 84.62 & 15.38 & 0.00 & 284.62 & II \\
\hline Private integrators $(\mathrm{n}=15)$ & 60.00 & 40.00 & 0.00 & 260.00 & III \\
\hline Public departments $(n=41)$ & 100.0 & 0.00 & 0.00 & 300.0 & $\mathrm{I}$ \\
\hline Private veterinarians $(n=69)$ & 5.80 & 24.64 & 69.57 & 136.23 & V \\
\hline Para-veterinarians $(\mathrm{n}=91)$ & 24.18 & 49.45 & 26.37 & 197.80 & IV \\
\hline
\end{tabular}


Table 3. Overall perceived effectiveness of AI service offered by the different dairy service delivery systems

\begin{tabular}{llcc}
\hline Sl. & Dairy service delivery systems & \multicolumn{2}{c}{ Artificial insemination services } \\
\cline { 3 - 4 } No. & & Weighted mean score & Rank \\
\hline 1 & Dairy co-operatives & 269.23 & II \\
2 & Private integrators & 268.00 & III \\
3 & Public departments & 294.63 & I \\
4 & Private veterinarians & 252.46 & V \\
5 & Para-veterinarians & 255.60 & IV \\
\hline
\end{tabular}

Note: Weighted mean score was calculated by dividing the sum of total scores for all the indicators of a particular system by the total number of indicators for the particular service

insemination service of para-veterinarians (264.84) was perceived to be not so effective as that of other service delivery systems.

Cost effectiveness: Dairy farmers perceived the insemination services of public departments (300.00) to be the cost effective followed by dairy co-operatives (284.62) and private integrators (260.00). However, the services of private veterinarians (136.23) and paraveterinarians (197.80) were perceived as less cost effective because of the high fees charged by them.

Overall perceived effectiveness of AI service offered by the different dairy service delivery systems: From the Table 3 , it is evident that the artificial insemination service offered by public departments (294.63) like veterinary dispensary and sub-centre were perceived to be overall effective followed by the dairy co-operatives (269.33) and private integrators (268.00). However, the insemination services of private veterinarians (252.46) and paraveterinarians (255.60) were perceived to be not so effective as other delivery systems.

\section{DISCUSSION}

AI service availed from different dairy service delivery systems: The paraveterinarians and private veterinarians are mostly personal localite and they have close association and credibility among the dairy farmers in the village. They are readily available to the clients when needed and were providing doorstep insemination services. Because of these reasons, farmers had predominantly availed the AI services from them. The farmers find it very difficult to bring the animals to the public veterinary institutions for insemination especially when the animal is in estrus.

Perceived effectiveness of AI service of different dairy service delivery systems: Timeliness: Public department (veterinary dispensary and sub-centres) was functioning routinely form 8.00 AM to 
12.00 PM and 3.00 PM to 5.00 PM everyday so that the farmers can get their animals inseminated in the cooler period of the day which is mostly preferred by the dairy farmers for better conception. The services of private veterinarians are available at the doorstep of the dairy farmers on call basis. Similar results for the timely delivery of AI service of para-veterinarians were reported by Hamdani (2013). The farmers reported that the inseminators and veterinarians of dairy co-operatives and private integrators are not available in time and so they prefer private veterinarians and para-veterinarians (Sangameswaran and Prasad, 2016).

Semen of varied breeds: The public department was maintaining their own breeding bull farms in Tamil Nadu with various indigenous and exotic breeds of cattle and buffalo such as Jersey (pure and cross bred), Holstein Friesian (pure and cross bred), Tharparkar, Kangayam, Red Sindhi and Murrah for semen production which are being regularly distributed to all veterinary dispensary and sub-centres. But the other insemination service providers viz., dairy co-operatives, private integrators, private veterinarians and para-veterinarians were are mostly using the semen either supplied by their agency or purchased from private farms or firms which is not heterogeneous in nature. Similar finding was reported by Simranjit et al. (2017) where semen from varied breeds was not available to the farmers in the dairy cooperative of Milkfed, Punjab.
Quality: The quality of the service offered by public department and private veterinarians can be attributed to the infrastructure and equipments available for providing insemination service even at the door step level as well as the knowledge and expertise about advance breeding techniques acquired from continuing education through training and workshops by the personnel of their service delivery system who were engaged in insemination. However, the results are contradicting with the findings of Kumar (2011) where majority of the respondents perceived the quality of artificial insemination services of public departments as average. Unlike veterinarians who are professionals, the inseminators engaged by the co-operatives and para-veterinarians are only trained personnel without proper scientific knowledge about the breeding techniques and hence their quality of service was not perceived to be equally effective when compared to other service providers.

Conception: The dairy farmers perceived better conception from the insemination service of the public departments, private veterinarians, dairy co-operatives and private integrators because of the availability of equipment for storage, thawing and handling of semen, supply of good quality semen coupled with the professional competency of veterinarians ensured better conception rate after artificial insemination. However, the conception with 
the insemination service of paraveterinarians was perceived to be not so effective because of the lack of scientific knowledge and technical expertise. This is similar to the findings of Rathod et al. (2014) wherein the para-veterinarians were unable to detect heat and hence the conception rate was relatively low even after frequent inseminations.

Cost effectiveness: The insemination service offered by the veterinarians in public department (veterinary dispensary and sub-centres) are charged between Rs.10/- and Rs. 15/- and sometimes it may be done free of cost during certain camps. This is in contradiction with the findings of Kumar (2011) wherein he reported that overwhelming majority of the respondents perceived that high price were charged for insemination services by the State Animal Husbandry Department. Also, the cooperatives and integrators were offering insemination services to their members at subsidized cost which made their service cost effective. However, the private veterinarians and para-veterinarians were charging high fees prices for the service rendered by them (Hamdani, 2013).

Overall perceived effectiveness of AI service offered by the different dairy service delivery systems: The artificial insemination service offered by public departments are good in quality and timely in delivery coupled with better conception in the dairy animals. This is contradictory to the findings of Jain et al. (2016) wherein he reported that the effectiveness of AI services by State Animal Husbandry Department was perceived as average. Though, the insemination services of private veterinarians and para-veterinarians (255.60) were perceived as timely and good quality in nature with better conception, the fees charged by them rendered their service as less cost effective and it could be the reason for low weighted mean scores.

It can be concluded that the insemination services of public department was perceived as best in terms of timeliness, quality, conception and cost effectiveness by the dairy farmers. The dairy farmers predominantly availed the insemination services of para-veterinarians as they were readily available even to render service in the door step of farmers. However, their service was not perceived to be quality and cost effective because of the lack of scientific knowledge and excess fees charged by them. The services of dairy cooperatives and private integrators were perceived to be of poor quality and not timely available but they were perceived to be cost effective with good conception rate. Though the service of private veterinarians were good quality and timely available with better conception rate, the dairy farmers perceived it as costly and hence overall it was perceived to be least effective among the various dairy service delivery systems. 


\section{REFERENCES}

Hamdani SA, 2013. Role dynamics of paraveterinary professionals in relation to delivery of livestock health services. Ph.D. thesis submitted to Indian Veterinary Research Institute (Deemed University), Izatnagar - 243122 (U.P.)

Jain AK, Sharma NK, Rajput DS, Meena OP and Mishra P, 2016. A study on farmer's view on delivery of veterinary services in terms of availability, efficiency and satisfaction. Vet Practitioner, 17 (2): 298300

Kumar P, 2011. Study on delivery system of the animal husbandry inputs in Banka district (Bihar). M.Sc. thesis, submitted to National Dairy Research Institute (Deemed University), Karnal, Haryana

Pushpa and Chandel BS, 2014. Effectiveness of artificial insemination in dairy cattles: Recent evidences from India's milking state of Gujarat. Indian Res J Ext Edu, 14 (4): $18-26$
Rathod P, Nikam TR, Landge S, Hatey A and Singh BP, 2014. Perception towards livestock breeding service delivery by dairy co-operatives. Indian Res J Ext Edu, 14 (2): $91-95$

Rathod P and Chander M, 2014. Identification of socio-economically important dairy innovations in India: A perspective of scientists. Proceedings of the first international conference of the Asia and Pacific Islands Rural Advisory Services (APIRAS); University of Zanjan, Iran, pp 101

Sangameswaran R and Prasad S, 2016. Extent of willingness to pay for dairy husbandry services by milk producers of Salem district of Tamil Nadu. Indian Res J Ext Edu, 16 (3): 67-71

Simranjit, Singh SS, Singh J, Kashyap N and Kansal SK et al., 2017. Perception of member dairy farmers about animal health care services and input facilities provided by milkfed. J Anim Res, 7 (5): 957-963 